\title{
A Temperature-Gated Nanovalve Self-Assembled from DNA to Control Molecular Transport Across
}

\section{Membranes}

\author{
Patrick M. Arnott $t^{\dagger}$ Stefan Howorka
}

${ }^{\dagger}$ Department of Biochemical Engineering, University College London, London, WC1E 7JE, United Kingdom

Department of Chemistry, Institute of Structural and Molecular Biology, University College London, London, WC1H 0AJ, United Kingdom.

Corresponding author, email: s.howorka@ucl.ac.uk 


\begin{abstract}
Nanopores are powerful nanodevices that puncture semifluid membranes to enable transport of molecular matter across biological or synthetic thin layers. Building advanced nanopores featuring more complex functions such as ambient sensing and reversible channel opening are of considerable scientific and technological interest but challenging to achieve with classical building materials. Here we exploit the predictable assembly properties of DNA to form a multifunctional nanovalve that senses temperature for controlled channel opening and tunable transport. The barrel-shaped valve is formed from solely seven oligonucleotides and is closed at ambient temperatures. At $>40^{\circ} \mathrm{C}$ a programmable thermosensitive lid opens the barrel to allow transport of small molecules across the membrane. The multifunctional DNA nanodevice may be used to create logic ionic networks, or to achieve controlled drug delivery from vesicles.
\end{abstract}

Keywords: DNA nanotechnology, nanopores, lipid bilayer, temperature, valve, fluorescence 
Nanopores are of general scientific and technological interest. They puncture synthetic semifluid membranes as a usually barrel-shaped conduit to transport water-soluble cargo across the hydrophobic divide. By exploiting this basic conduit function, nanopores have been applied for the electrical detection of analytes, ${ }^{1-9}$ as highlighted by the step-changing portable DNA sequencing. ${ }^{10-14}$ The sensing principle relies on the passage of individual analytes through an electrolyte-filled pore that leads to transient detectable changes in electrical read-out. To achieve performance in the sensing applications, barrels are usually re-engineered or newly designed pores composed of multiple protein or peptide subunits but can also be assembled from synthetic components. ${ }^{15-20}$

Expanding the function beyond stiff membrane-puncturing barrels can produce advanced nanopores of additional biotechnological interest. Following inspiration from biology,,$^{2-4,7,8,18,21-30}$ exciting targets are channels that sense ambient stimuli such as temperature and nanomechanically translate the signal into reversible channel opening. ${ }^{29,31,32}$ Synthetically replicating the challenging triple function of temperature sensing, nanomechanics, and output would constitute highly advanced bottom-up design. ${ }^{33}$ In addition, temperature-gated nanovalves could be key parts in drug delivery vesicles ${ }^{34}$ or synthetic cells. Unfortunately, classical building materials such as polypeptides are not ideal building materials for this purpose due to the intricate and difficult-to-predict folding, despite considerable success. ${ }^{35-37}$

Here we report on an artificial temperature-gated nanovalve composed of DNA. DNA is an excellent material for rationally designing nanoscale architectures ${ }^{38-48}$ due to the highly predictable hybridization between DNA strands, the detailed knowledge of DNA structure, 
dedicated software to design of nanostructures, ${ }^{49}$ and modern chemical tools to synthesize DNA molecules. Our DNA-based nanovalve takes advantage of barrel-shaped DNA nanopores ${ }^{50-53}$ that carry tethered hydrophobic anchors for membrane insertion..$^{22,54-59}$ There is also an understanding of how to strategically position a DNA strand to block the channel lumen and reopen it by hybridization of a ligand strand. ${ }^{60}$ However, an unmet challenge is to build a temperature-gated nanovalve that reversibly opens and closes to tuneably control transport of cargo across a bilayer.

\section{Results and Discussion}

The temperature-gated molecular valve was designed to feature two main parts: a membranespanning barrel-shaped nanopore, and at its top a re-sealable lid (Figure 1A). The cylindrical nanopore is formed from six DNA strands that fold into six duplexes and are arranged in hexagonal fashion to enclose a channel of $2 \mathrm{~nm}$ internal width (Figure 1A,C; DNA strands in blue). The duplexes are interlinked with loops, and two of these are elongated (Figure 1A,B). The second part of the valve, the re-sealable DNA-based lid, is hybridized to the two elongated loops at room temperature to block the entrance to the channel (Figure 1A,C; lid in red). However, temperatures above $40{ }^{\circ} \mathrm{C}$ dissociate the lid strand selectively from loop segments $2-4$ but not segment 1 to allow reversible lid opening and closing (Figure 1A,C). Selective dissociation at segments 2-4 was attained via designed melting temperatures of around $40{ }^{\circ} \mathrm{C}$ which is lower than $62.8^{\circ} \mathrm{C}$ for the duplex between segment 1 and the lid. As final part of the rational design, the molecular valve is equipped with four cholesterol groups to insert the negatively charged pore into the hydrophobic lipid membrane (Figure 1A,D). 
A

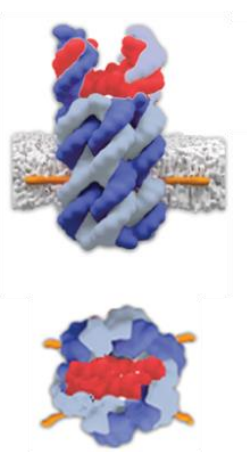

tNP

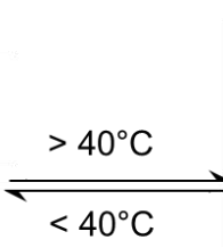

.
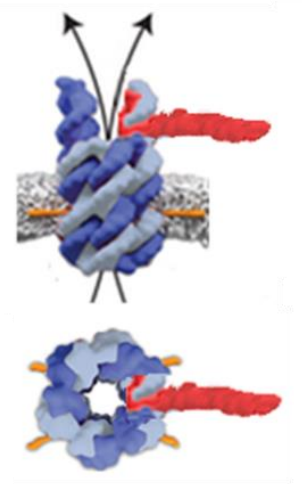

B

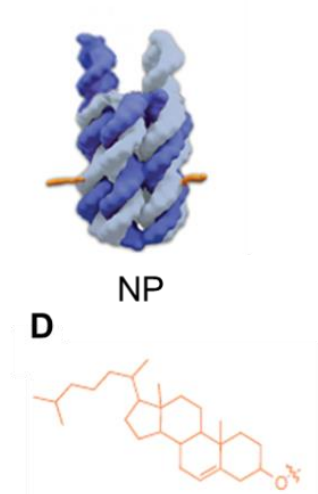

C

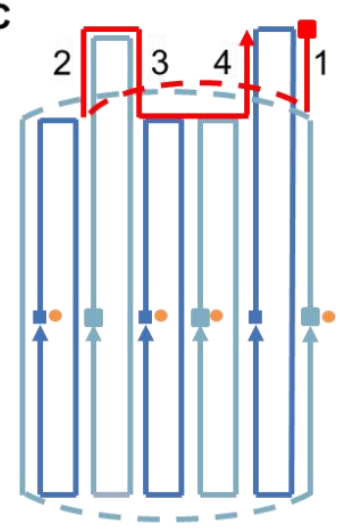

Figure 1. A temperature-gated DNA nanopore, termed tNP, reversibly opens and closes to control transport of molecular cargo across a bilayer membrane. (A) Side and top-view of tNP. A thermosensitive lid (red) blocks the pore's opening but dissociates at temperature $>40{ }^{\circ} \mathrm{C}$ to open the channel entrance. A small segment of the lid remains hybridized to the pore at $>40{ }^{\circ} \mathrm{C}$ to allow for reversible channel opening and closing. The lid dissociates from the pore above 60 ${ }^{\circ} \mathrm{C}$. The pore is composed of six component DNA strands highlighted alternatingly in light blue and dark blue. The four cholesterol anchors (orange) insert tNP into the hydrophobic lipid bilayer membrane. (B) Pore NP does not feature the lid of tNP. The elongated loop regions at the left and right of the pore allow for the binding of the thermosensitive lid. (C) 2D map of tNP illustrating the composition from six pore-forming strands and the lid. The duplex segments 1-4 between pore strands and the lid have designed melting temperature of $62.8^{\circ} \mathrm{C}, 40{ }^{\circ} \mathrm{C}, 40{ }^{\circ} \mathrm{C}$, and $39.8{ }^{\circ} \mathrm{C}$, respectively. (D) Structure of the cholesterol anchor used to insert tNP inside the bilayer membrane.

The rationally designed temperature-gated nanopore, tNP, (Figure 1A,C) was self-assembled from the seven constituent DNA strands (for sequences see Supporting Information, Tables S1 
and S2, Figure S1). An equimolar mixture of the oligonucleotides was heated and cooled to yield a single assembly product, as shown by a single band in gel electrophoresis (Figure 2A). A low extent of gel smearing is attributed to the hydrophobic lipid anchors and the interaction with the gel matrix or the formation of possible oligomers for pores with 4 cholesterols (see second band in Figure 2A).

Two variants of the molecular valve with fluorophores were formed to facilitate analysis of the valve's membrane binding and dynamic opening activity. In the first tNP variant, a Cy3 dye was incorporated at the lid strand to help track membrane binding with fluorescence microscopy. In a second variant, a Cy5 dye was additionally included at the pore entrance (Figure S1, Tables S1 and S2) to investigate lid opening, as discussed further below. The two tNP variants with fluorophores successfully formed as confirmed by single discrete bands in gel electrophoresis (Figure 2A, Figure S2).

To monitor membrane binding, tNP Cy3 was added to giant unilamellar vesicles (GUVs) of phospholipid 1-palmitoyl-2-oleoyl-sn-glycero-3-phosphocholine (POPC). Subsequent fluorescence microscopic analysis of the GUVs confirmed binding as seen as a ring of $\mathrm{Cy} 3$ emission around the vesicle (Figure 2B, Figure S3). Successful membrane interaction was additionally established with small unilamellar vesicles (SUVs) and an electrophoretic gel-shift assay. In the assay, free tNP migrates into the gel while tNP bound to larger SUVs do not move into the gel (Figure 2C). Hence, increasing lipid SUV concentrations led to more membrane binding as indicated by a more intense gel band for tNP-SUV and a weaker gel band for free tNP. There are no additional gel bands (Figure 2C) implying that the pore remains intact upon 
membrane binding. We cannot rule out that the pore disintegrates within the membrane and not produce an additional band. This is, however, not likely because membrane binding and insertion of DNA nanopores usually leads to the thermal stabilization as shown in UV melting profiles. ${ }^{60}$

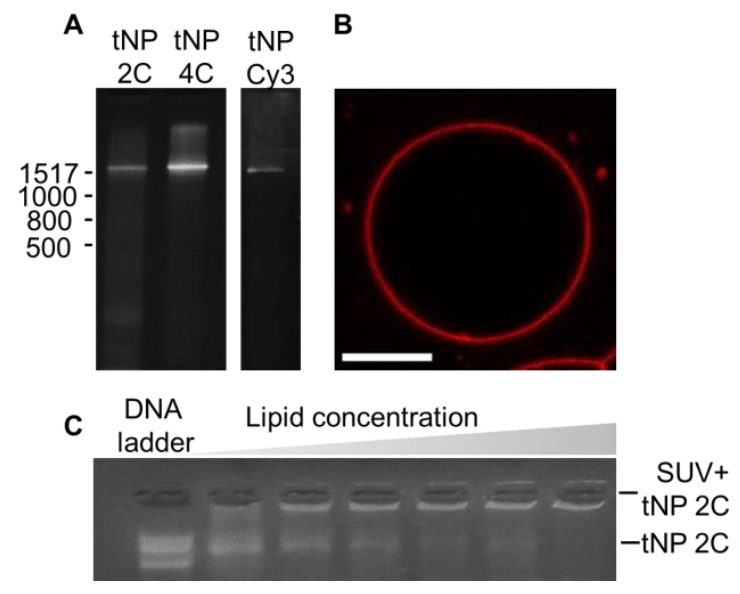

Figure 2. The temperature-gated nanopore tNP is self-assembled from DNA and binds to lipid bilayer membranes. (A) Assembly of the pore is confirmed by $10 \%$ polyacrylamide gel electrophoresis (PAGE). Lane 1 and 2, NP with 2 and 4 cholesterols anchors, respectively. Lane 3, tNP carrying a Cy3 dye. (B) Membrane binding of tNP-Cy3 with 4 cholesterols by fluorescence microscopic analysis of a POPC GUV's using excitation at $550 \mathrm{~nm}$ and emission at $570 \mathrm{~nm}$. Scale bar, $10 \mu \mathrm{m}$. (C) Agarose gel electrophoretic analysis on the membrane binding of tNP carrying two cholesterols to DOPE/DOPC SUVs. The amount of vesicles increased from $0-$ $270 \mu \mathrm{M}$. Vesicle-bound tNP stays within the wells of the agarose gel. The assay was conducted at $4^{\circ} \mathrm{C}$. 
To demonstrate reversible temperature-controlled gating, the molecular valve variant equipped with a Cy3/Cy5 pair was used (Figure 3A, Figure S1). In tNP's closed state at RT, Cy3 on the lid is proximal to $\mathrm{Cy} 5$ on the pore leading to $\mathrm{Cy} 3$ quenching. By contrast, at temperatures $>40{ }^{\circ} \mathrm{C}$ the lid strand is expected to dissociate at duplex segments $2-4$ from the pore, while remaining hybridized at segment 1 . Upon heating, the increased distance to the quencher dye Cy5 should increase the fluorescence signal of Cy3 (Figure 3A, Figure 1C).

Tracking Cy3 emission upon heating and cooling confirmed the temperature-induced opening and closing of the molecular valve. The corresponding kinetic $\mathrm{Cy} 3$ trace shows at RT a weak signal indicating strong quenching by proximal Cy5 in closed tNP (Figure 3B). By contrast, heating to $55{ }^{\circ} \mathrm{C}$ increased the $\mathrm{Cy} 3$ signal (Figure 3B) in line with lid dissociation from segments 2-4 (Figure 3A). Cooling of tNP again lowered the fluorescence signal (Figure 3B) due to the regained $\mathrm{Cy} 3 / \mathrm{Cy} 5$ proximity upon lid reannealing (Figure $3 \mathrm{~A}$ ). Reversible opening and closing was repeated in six heating-and-cooling cycles (Figure 3C) yielding an average fluorescence recovery time of $12.6 \pm 1.0 \mathrm{~min}$. The minutes-long recovery time is predominantly a consequence of the experimental set-up and does not reflect the inherent rate for duplex association. The experimental set-up involved leaving the heated cuvette including sample in the fluorescence spectrophotometer and letting the sample/cuvette cool to room temperature, leading to similar decay in fluorescence and temperatures (Figure 3B). By contrast, the typical inherent duplex association time scales are in the range of seconds. ${ }^{61}$ 


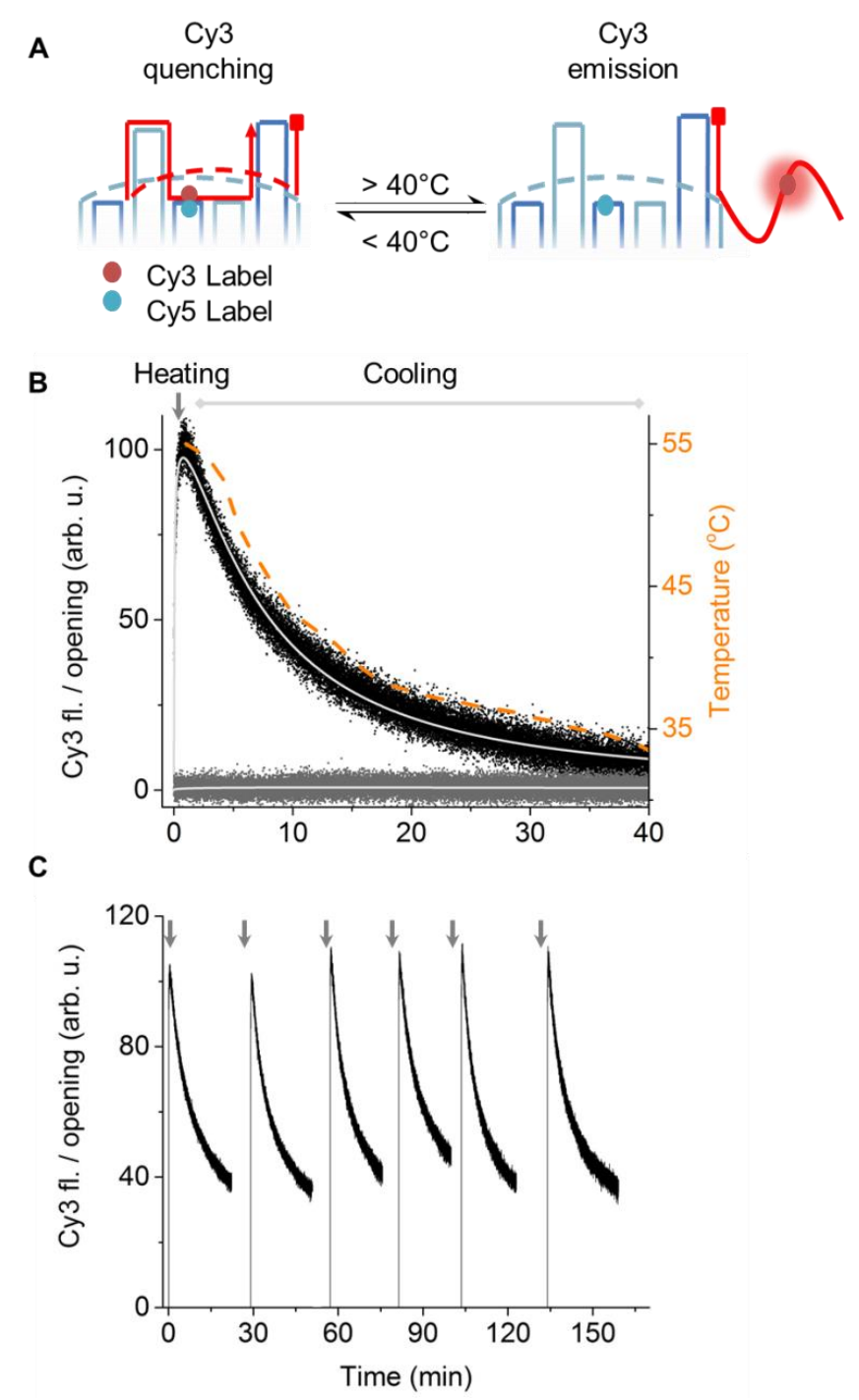

Figure 3. Reversible opening and closing of the temperature-gated valve. (A) 2D map of tNP's top which undergoes thermosensitive opening of the lid. The opening separates the $\mathrm{Cy} 3$ from the quencher fluorophore $\mathrm{Cy} 5$ to yield a stronger $\mathrm{Cy} 3$ fluorescence signal due to weakened quenching by proximal Cy5. (B) Kinetic trace of $\mathrm{Cy} 3$ fluorescence emission indicating lid opening of tNP upon heating to $55^{\circ} \mathrm{C}$ and closing upon cooling to room temperature (RT). Fluorescence was measured at $570 \mathrm{~nm}$ using excitation at $550 \mathrm{~nm}$. The trace of tNP kept at RT is shown in gray. $100 \%$ is defined as the fully unbound fluorophore strand. The temperature of the sample recorded in the process of cooling the sample from $55^{\circ} \mathrm{C}$ is shown in an orange dashed 
line. (C) Kinetic $\mathrm{Cy} 3$ emission traces illustrating repeated and sequential opening and closing of a tNP. The experiments in B and C were performed in bulk solution and not in lipid membrane environment.

A control experiment confirmed that the lid strand remains associated to segment 1 of the NP pore at $55^{\circ} \mathrm{C}$. A control oligonucleotide designed to bind solely to pore segment 1 was added in 20 -fold molar access. The oligonucleotide should not interfere if the lid strand remains bound to segment 1 . Indeed, at up to $55^{\circ} \mathrm{C}$, the fluorescence decay traces were indistinguishable for the pore with and without control oligonucleotide (Figure S4). However, at temperatures where the lid dissociates (at $75{ }^{\circ} \mathrm{C}$ and higher), the control oligonucleotide competitively bound to segment 1 and interfered with re-annealing of the lid as indicated by a higher remaining fluorescence upon cooling (Figures S4). The temperature-dependent opening of tNP was also confirmed by gel electrophoresis (Figure S5).

Having established thermosensitive opening and closing, the molecular valve was used for temperature-controlled transport of molecular cargo. The corresponding transport assay is schematically shown in Figure 4A. Molecular valve tNP is inserted inside a lipid bilayer of a SUV of $106 \mathrm{~nm}$ diameter which encapsulates reporter dye sulfo rhodamine B (SRB) (Figure S6). In tNP's closed state, the highly concentrated fluorophore remains inside the vesicle where it is self-quenched.$^{60}$ By contrast, temperature-controlled opening of tNP is expected to release SRB to yield a stronger fluorescence signal of the diluted dye (Figure 4A). 

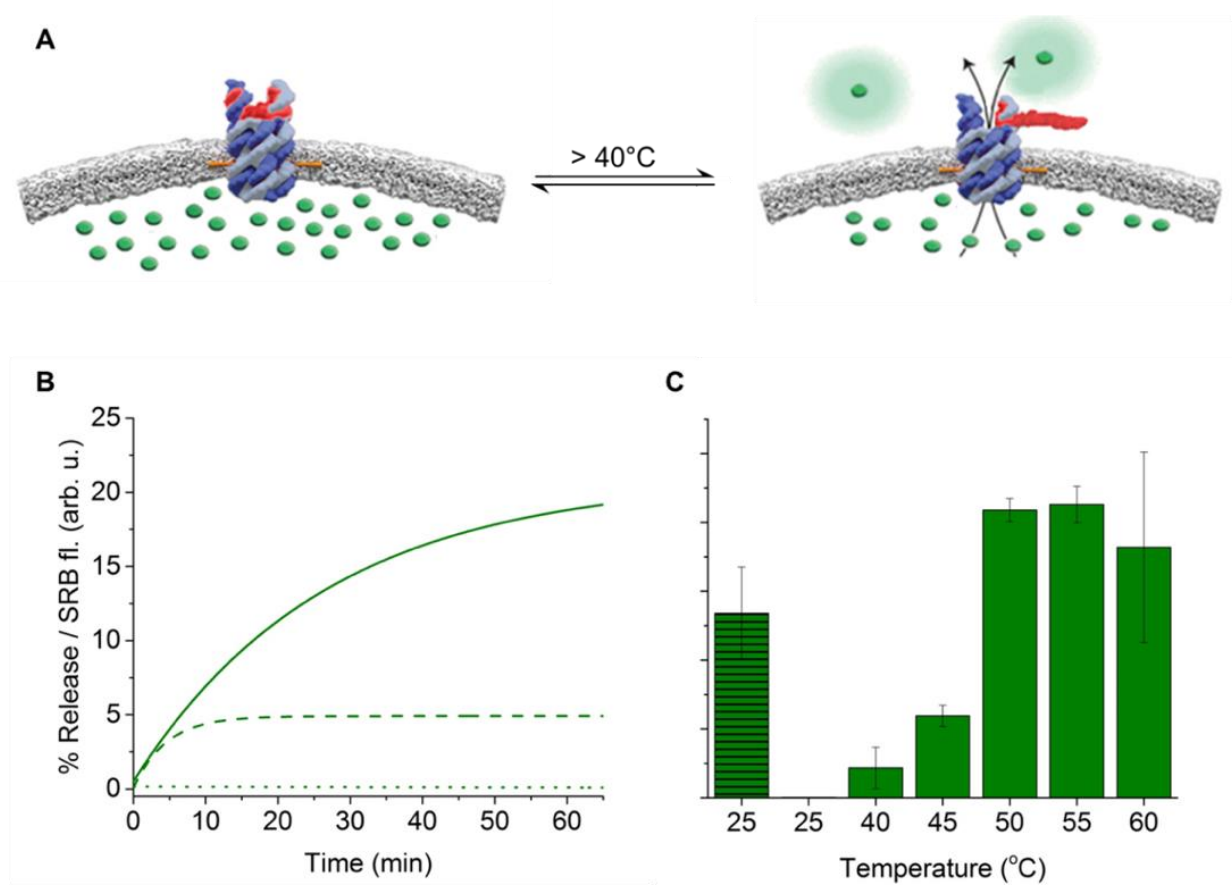

Figure 4. tNP permits temperature-controlled transport of molecular cargo across a bilayer. (A) tNP inserted inside a lipid bilayer of a SUV. The vesicle is filled with fluorophore sulfo rhodamine $\mathrm{B}(\mathrm{SRB})($ green dots). In its closed state tNP does not permit passage of the encapsulated dye which is contact-quenched at its high concentration inside the vesicle. Temperatures $>40{ }^{\circ} \mathrm{C}$ open the lid of tNP to release SRB which becomes fluorescent at the lower dye concentration. (B) Quantifying valve-mediated release of SRB via kinetic fluorescence traces. Vesicles with inserted tNP were left at room temperature (dotted line), or heated to $40{ }^{\circ} \mathrm{C}$ (dashed line) or $55^{\circ} \mathrm{C}$ (solid line). SRB fluorescence was excited at $564 \mathrm{~nm}$ measured at $585 \mathrm{~nm}$. The plots represent fits of raw data shown in Figure S7. (C) Histogram of net fluorescence increase upon heating of tNP-vesicles (from $25^{\circ} \mathrm{C}$ to $60{ }^{\circ} \mathrm{C}$ ) and NP-vesicles at $25^{\circ} \mathrm{C}$ (box with lines). The net fluorescence increase is from the traces in $\mathrm{C}$ and Table S3. The net increase represents the fluorescence signal after heating minus the fluorescence signal at $0 \mathrm{~min}$, and normalization to the total fluorescence signal upon rupturing of the vesicles with detergent. The data represent averages and standard deviations from at least 3 independent experiments. 
For the release assay, we first demonstrated the ability of the closed-state tNP to retain the molecular cargo inside the vesicles without dye leakage. In agreement, adding tNP at RT to the vesicles caused only a small increase in fluorescence $(0.02 \pm 0.03 \%)$ (Figure 4C, Figure S7, Table S3) suggesting that the closed nanodevice blocks transport. It is certain that the tNP pore spans the membrane because control pore NP without a lid (Figure 1B, Figure S1) caused efflux of molecular cargo to yield a fluorescence increase of $13.4 \pm 3.4 \%$ (Figure 4C, Figure S7, Table $\mathrm{S} 3 ; 100 \%$ release is total amount of fluorescence obtained upon rupturing vesicles with a detergent). In light of successful release by NP, data on closed tNP also suggest that the pore is inserting into the SUV without major rupturing of the membrane (Figure S7). tNP is inserted likely in upright orientation as shown in Fig. 1 due to the low position of the cholesterol in the structure and the energetically more favorable insertion into the bilayer membrane. The insertion orientation does not affect the function of $\mathrm{tNP}$ as temperature-controlled opening can be achieved with pores in both orientations.

After confirming successful membrane insertion of tNP, we analyzed the molecular valve's temperature-gated control of transport. SUVs with inserted tNP were exposed in parallel experiments to temperatures of $40{ }^{\circ} \mathrm{C}$ to $60{ }^{\circ} \mathrm{C}$ in $5{ }^{\circ} \mathrm{C}$ increments. The release of fluorophore was apparent in kinetic traces for SRB emission as shown for $40{ }^{\circ} \mathrm{C}$ and $55{ }^{\circ} \mathrm{C}$ (Figure 4B). When quantified as net fluorescence increase, $40{ }^{\circ} \mathrm{C}$ caused a release of $2.17 \pm 1.50 \%$ (Figure 4C, Table S3) which is more than 100-times higher than at room temperature. By comparison, 55 ${ }^{\circ} \mathrm{C}$ led to an even 1000 -fold increase to $21.3 \% \pm 1.3 \%$ (Figure 4C). The release data (Figure 4C) show a maximum change between $45{ }^{\circ} \mathrm{C}$ and $50{ }^{\circ} \mathrm{C}$ (Table S3). The inferred midpoint of approximately $47{ }^{\circ} \mathrm{C}$ is higher than the nominal melting temperature of $40{ }^{\circ} \mathrm{C}$ for the lid-pore 
interactions but in line with the multivalency effects caused by the three duplex segments. The release at up to $55^{\circ} \mathrm{C}$ is fully consistent with a thermosensitive lid that remains bound to the pore via duplex region 1 with a melting temperature of $62.8^{\circ} \mathrm{C}$ (Figure 4A). The gradual increase of release with higher temperature (Figure 4C) reflects the molecular nature of the valve. As shown in Figure 1 and Figure 3, the lid is reversibly hybridized via three duplex segments to the pore. Complete opening of the pore requires dissociation at all three segments. Consequently, increasing the temperature just above the nominal melting temperature of $40{ }^{\circ} \mathrm{C}$ will likely unzip one or two DNA segments but not all three due to the noted multivalency effect. This translates into the observed intermediate release rate. Higher temperatures will lead to a more extensive opening and a higher release rate (Figure 4C). The notable increase in standard deviation of the measurements at $60{ }^{\circ} \mathrm{C}$ (Figure 4C, Table S3) may indicate that the thermal stability of the nanodevice is beginning to be compromised at this high temperature.

\section{Conclusions}

This study has described a synthetic temperature-gated nanovalve that controls molecular transport across biological membranes. The nanodevice advances the field of supramolecular chemistry and synthetic biology as chemical building blocks were assembled into a multifunctional biomimetic nanodevice that spans biological membranes, senses the ambient, undergoes a triggered nanomechanical change, and tuneably controls transport. The nanovalve also advances DNA nanotechnology. A previous synthetic DNA channel irreversibly opened in response to a DNA trigger ${ }^{60}$ and is hence represents a one-off mechanism. The present DNA pore is different as it responds to temperature and reversibly opens and closes. To attain the desired temperature-control, the valve features carefully designed lid duplex segments of which 
three dissociated at above $40{ }^{\circ} \mathrm{C}$ but the forth only above $63{ }^{\circ} \mathrm{C}$. This allows lid dissociation at three segments while maintaining lid association at the forth to keep the link to the DNA pore. The rational design with DNA also afford easier engineering and defined nanomechanical changes compared to a previous thermally triggered protein pore carrying a polypeptide that adopts different temperature-dependent conformational fluctuations. ${ }^{62}$ As a consequence of the high-degree of rational design with DNA, the temperature-gated nanovalve shows an 1000-fold increase in flux upon thermal triggering. This has not been achieved previously with any other organic and inorganic nanodevice. The temperature-gated pore complements light-gated pores that are based on covalently attaching a channel blocker via a photoresponsive linker to a biological channel. ${ }^{63-66}$ Finally, the DNA molecular valve extends the range of biomimetic devices from DNA which include molecular motors, ${ }^{40,67-69}$ antibody-like structures, cytoskeletal scaffolds, ${ }^{70}$ and synthetic enzymes. ${ }^{71}$ The temperature-gated device could be adapted for different temperatures and may be used in future for research, controlled drug delivery vesicles or to create synthetic versions of cells.

\section{Methods}

Materials: Unmodified and cholesterol-labeled DNA oligonucleotides were purchased from Integrated DNA Technologies on a 100 nmol scale with HPLC or PAGE purification. 1,2dioleoyl-sn-glycero-3-phosphoethanolamine (DOPE), 1,2-dioleoyl-sn-glycero-3-phosphocholine (DOPC), and 1-palmitoyl-2-oleoyl-sn-glycero-3-phosphocholine (POPC) were procured from Avanti Polar Lipids. All other reagents and solvents were purchased from Sigma-Aldrich. 
DNA assembly: DNA sequences and 2D DNA maps are provided in Table S1 and Figure S1, respectively. Equimolar mixtures of DNA oligonucleotides $(1 \mu \mathrm{l}$ each, stock concentration of $100 \mu \mathrm{M}$ ) were dissolved in $20 \mathrm{mM} \mathrm{MgCl} 2$ to a final volume of $100 \mu$. Folding was achieved on a BioRad PCR thermocycler using heating to $95^{\circ} \mathrm{C}$ for $10 \mathrm{~min}$, cooling for $0.5^{\circ} \mathrm{C}$ per min to 60 ${ }^{\circ} \mathrm{C}$, followed by cooling at $1{ }^{\circ} \mathrm{C}$ per min to $20^{\circ} \mathrm{C}$.

SDS PAGE: The assembled DNA nanostructure and component DNA oligonucleotides were analyzed with commercial 10\% polyacrylamide gels (BioRad) in 1 x TBE (89 mM Tris-borate and $2 \mathrm{mM}$ EDTA, pH 8.3). For gel loading, a solution of DNA $(5 \mu \mathrm{l}, 1 \mu \mathrm{M})$ was mixed with gel loading dye $(5 \mu \mathrm{l})$. The gel was run for $90 \mathrm{~min}$ at $70 \mathrm{~V}$ and at $4{ }^{\circ} \mathrm{C}$. The bands were then visualized with staining by ethidium bromide and UV illumination. A 100 bp marker (New England Biolabs) was used as a reference standard.

Preparation of SUVs: A solution of lipids DOPE $(0.3 \mathrm{mmol}, 50 \mu \mathrm{l})$ and DOPC $(0.7 \mathrm{mmol}$, $550 \mu \mathrm{l})$ in chloroform was added to a $5 \mathrm{ml}$ round bottom flask. The solvent was removed using a rotary evaporator to yield a thin film, which was subsequently dried under ultrahigh vacuum for $3 \mathrm{~h}$. The lipid was re-suspended in buffer $0.3 \mathrm{M} \mathrm{KCl}, 15 \mathrm{mM}$ Tris $\mathrm{pH} 8.0$ or PBS (10 mM PO${ }^{3-}$, $154 \mathrm{mM} \mathrm{NaCl}, \mathrm{pH}=7.4$ ) (ionic strength of $0.179 \mathrm{M})(1 \mathrm{ml}$ ), and the solution was sonicated for $30 \mathrm{~min}$ at RT. SUVs were left to equilibrate for $5 \mathrm{~h}$ and used within $24 \mathrm{~h}$. The suspension was gently resuspended $2 \mathrm{~s}$ before use. SUVs were subjected to dynamic light scattering (DLS) to confirm the vesicles' diameter using a Zetasizer Nano S from Malvern.

GUV preparation: POPC in chloroform $(6 \mu 1,10 \mathrm{mg} / \mathrm{ml})$ was added to an indium tin oxide coated glass plate and allowed to dry. To the POPC film sucrose (300 $\mu \mathrm{l}, 1 \mathrm{M})$ was added within a rubber ring ( $2 \mathrm{~cm}$ diameter). Plates were inserted into Nanion Vesicle Prep Pro and GUV 
formation protocol with the following setting was used: 3 min rise time, frequency of $10 \mathrm{~Hz}$, amplitude of $3 \mathrm{mV}$ at $60{ }^{\circ} \mathrm{C}$, time $120 \mathrm{~min}$, and fall time of $5 \mathrm{~min}$.

SUV binding and agarose gel electrophoresis: The binding of NP to membrane vesicles was monitored by mixing DNA nanopore solutions $(10 \mu \mathrm{l}, 1 \mu \mathrm{M})$ to a suspension of DOPC/DOPE SUVs $(1 \mathrm{mM}$ lipid, $0-21.6 \mu$, final concentration of $0-270 \mu \mathrm{M})$. The NP SUV mixture was incubated for $20 \mathrm{~min}$ at RT. The mix was analyzed using $2 \%$ agarose gels in TAE buffer (40 $\mathrm{mM}$ Tris-acetate, $1 \mathrm{mM}$ EDTA, $\mathrm{pH}$ 8.3). For gel analysis, the mixture of DNA and SUVs (40 $\mu 1)$ was combined with a solution $(10 \mu \mathrm{l})$ of $60 \%$ glycerol. The gel was run at $60 \mathrm{~V}$ for $90 \mathrm{~min}$ at 4 ${ }^{\circ} \mathrm{C}$. The gel bands were visualized by ultraviolet illumination after staining with ethidium bromide solution. A 100-base-pair marker (New England Biolabs) was used as the reference standard.

Cy3 emission assay: The extent of opening of tNP $\mathrm{Cy} 3 / \mathrm{Cy} 5$ was monitored by kinetic analysis of Cy3 emission with a fluorescence spectrophotometer. To a quartz cuvette DI water (120 $\mu \mathrm{l})$ and DNA nanopore $(30 \mu 1,1 \mu \mathrm{M})$ were added. Samples were then left at RT or heated to the indicated temperature for 4 min followed by cooling to RT. Cy3 fluorescence was monitored at $570 \mathrm{~nm}$ using excitation at $550 \mathrm{~nm}$.

Preparation of fluorophore-filled SUVs and release assay: A solution of lipids DOPE ( 0.3 $\mathrm{mmol}, 50 \mu \mathrm{l})$ and $\mathrm{DOPC}(0.7 \mathrm{mmol}, 550 \mu \mathrm{l})$ in chloroform was added to a $5 \mathrm{ml}$ round bottom flask. The solvent was removed using a rotary evaporator to yield a thin film, which was subsequently dried under ultrahigh vacuum for $3 \mathrm{~h}$. The lipid was re-suspended in buffer $0.3 \mathrm{M}$ $\mathrm{KCl}, 15 \mathrm{mM}$ Tris $\mathrm{pH} 8.0$ or PBS $(1 \mathrm{ml})$, containing fluorophore sulfo rhodomaine B (SRB) at a concentration of $50 \mathrm{mM}$. The solution was sonicated for $30 \mathrm{~min}$ at RT. Subsequently, the solution was purified with a NAP-10 column (GE Healthcare). Purified SUVs were left to 
equilibrate for $5 \mathrm{~h}$ and used within $24 \mathrm{~h}$. SUVs were subjected to dynamic light scattering (DLS) with a Malvern Zetasizer Nano $\mathrm{S}$ to confirm the vesicles' diameter. The suspension was gently resuspended $2 \mathrm{~s}$ prior to use.

For assaying temperature-dependent fluorophore release, a $10 \mathrm{~mm}$ quartz cuvette was filled with a SUV suspension carrying encapsulated SRB $(120 \mu \mathrm{l})$. Fluorescence was monitored at 585 $\mathrm{nm}$ using excitation at $564 \mathrm{~nm}$. To initiate release, DNA nanopore $(30 \mu \mathrm{l}, 1 \mu \mathrm{M})$ was added under mixing, and fluorescence was monitored. For temperature-induced release, samples were removed periodically ( $5 \mathrm{~min}$ ), heated in a metal block to the set temperature, and re-inserted into the fluorescence spectrophotometer to measure fluorescence. At the end of the 60 min-long temperature runs, samples were mixed with Triton X-100 to rupture vesicle membrane and determine the maximum SRB release. All experiments on release at different temperatures were carried out with separate samples

\section{ASSOCIATED CONTENT}

Supporting Information. A table with names, modifications and sequences of DNA oligonucleotides used for folding DNA nanopores; a table with names and compositions of DNA nanopores; 2D maps of DNA nanopores; gel electrophoretic analysis on formation of DNA nanopores; confocal images showing insertion of tNP into membrane vesicles; fluorescence emission traces on the thermal stability of tNP; gel electrophoretic analysis demonstrating tNP's temperature-triggered opening; dynamic light scattering data of PC/PE SUVs; data quantifying the temperature-controlled and tNP-mediated transport of reporter dye from bilayer vesicles; table with data on the release of reporter fluorophore from vesicles. This material is available free of charge via the Internet at http://pubs.acs.org. 


\section{AUTHOR INFORMATION}

\section{Corresponding Author}

s.howorka@ucl.ac.uk

\section{Author Contributions}

The manuscript was written through contributions of all authors. All authors have given approval to the final version of the manuscript.

\section{ACKNOWLEDGMENT}

S.H. and P.A. acknowledge support by the National Physical Laboratory and the EPSRC Centre for Doctoral Training in Bioprocess Engineering Leadership (EP/L01520X/1) for financial support and the EngD studentship for P.A. S.H. is supported by the EPSRC (EP/N009282/1), the BBSRC (BB/M025373/1, BB/N017331/1), and the Leverhulme Trust (RPG-2017-015).

\section{REFERENCES}

1. Wang, G.; Wang, L.; Han, Y.; Zhou, S.; Guan, X. Nanopore Stochastic Detection: Diversity, Sensitivity, and Beyond. Acc. Chem. Res. 2013, 46, 2867-2877.

2. Stoloff, D. H.; Wanunu, M. Recent Trends in Nanopores for Biotechnology. Curr. Opin. Biotechnol. 2013, 24, 699-704. 
3. Reiner, J. E.; Balijepalli, A.; Robertson, J. W. F.; Campbell, J.; Suehle, J.; Kasianowicz, J. J. Disease Detection and Management Via Single Nanopore-Based Sensors. Chem. Rev. 2012, $112,6431-6451$

4. Miles, B. N.; Ivanov, A. P.; Wilson, K. A.; Dogan, F.; Japrung, D.; Edel, J. B. Single Molecule Sensing with Solid-State Nanopores: Novel Materials, Methods, and Applications. Chem. Soc. Rev. 2013, 42, 15-28.

5. Venkatesan, B. M.; Bashir, R. Nanopore Sensors for Nucleic Acid Analysis. Nat. Nanotechnol. 2011, 6, 615-624.

6. $\quad$ Litvinchuk, S.; Tanaka, H.; Miyatake, T.; Pasini, D.; Tanaka, T.; Bollot, G.; Mareda, J.; Matile, S. Synthetic Pores with Reactive Signal Amplifiers as Artificial Tongues. Nat. Mater. 2007, 6, 576-580.

7. Movileanu, L. Interrogating Single Proteins through Nanopores: Challenges and Opportunities. Trends Biotechnol. 2009, 27, 333-341.

8. Howorka, S.; Siwy, Z. Nanopore Analytics: Sensing of Single Molecules. Chem. Soc. Rev. 2009, 38, 2360-2384.

9. Wei, R.; Martin, T. G.; Rant, U.; Dietz, H. DNA Origami Gatekeepers for Solid-State Nanopores. Angew. Chem. Int. Ed. 2012, 51, 4864-4867.

10. Quick, J.; Loman, N. J.; Duraffour, S.; Simpson, J. T.; Severi, E.; Cowley, L.; Bore, J. A.; Koundouno, R.; Dudas, G.; Mikhail, A.; Ouedraogo, N.; Afrough, B.; Bah, A.; Baum, J. H.; Becker-Ziaja, B.; Boettcher, J. P.; Cabeza-Cabrerizo, M.; Camino-Sanchez, A.; Carter, L. L.; 
Doerrbecker, J., et al. Real-Time, Portable Genome Sequencing for Ebola Surveillance. Nature 2016, 530, 228-232.

11. Cherf, G. M.; Lieberman, K. R.; Rashid, H.; Lam, C. E.; Karplus, K.; Akeson, M. Automated Forward and Reverse Ratcheting of DNA in a Nanopore at 5-Angstrom Precision. Nat. Biotechnol. 2012, 30, 344-348.

12. Manrao, E. A.; Derrington, I. M.; Laszlo, A. H.; Langford, K. W.; Hopper, M. K.; Gillgren, N.; Pavlenok, M.; Niederweis, M.; Gundlach, J. H. Reading DNA at Single-Nucleotide Resolution with a Mutant Mspa Nanopore and Phi29 DNA Polymerase. Nat. Biotechnol. 2012, 30, 349-353.

13. Deamer, D.; Akeson, M.; Branton, D. Three Decades of Nanopore Sequencing. Nat. Biotechnol. 2016, 34, 518-524.

14. Heerema, S. J.; Dekker, C. Graphene Nanodevices for DNA Sequencing. Nat. Nanotechnol. 2016, 11, 127-136.

15. Bayley, H.; Jayasinghe, L. Functional Engineered Channels and Pores. Mol. Membr. Biol. 2004, 21, 209-220.

16. Sakai, N.; Matile, S. Synthetic Ion Channels. Langmuir 2013, 29, 9031-9040.

17. Vargas Jentzsch, A.; Hennig, A.; Mareda, J.; Matile, S. Synthetic Ion Transporters That Work with Anion-Pi Interactions, Halogen Bonds, and Anion-Macrodipole Interactions. Acc. Chem. Res. 2013, 46, 2791-2800.

18. Gokel, G. W.; Negin, S. Synthetic Ion Channels: From Pores to Biological Applications. Acc. Chem. Res. 2013, 46, 2824-2833. 
19. Montenegro, J.; Ghadiri, M. R.; Granja, J. R. Ion Channel Models Based on SelfAssembling Cyclic Peptide Nanotubes. Acc. Chem. Res. 2013, 46, 2955-2965.

20. Zhao, Y.; Cho, H.; Widanapathirana, L.; Zhang, S. Conformationally Controlled Oligocholate Membrane Transporters: Learning through Water Play. Acc. Chem. Res. 2013, 46, 2763-2772.

21. Maglia, G.; Heron, A. J.; Hwang, W. L.; Holden, M. A.; Mikhailova, E.; Li, Q. H.; Cheley, S.; Bayley, H. Droplet Networks with Incorporated Protein Diodes Show Collective Properties. Nat. Nanotechnol. 2009, 4, 437-440.

22. Howorka, S. Building Membrane Nanopores. Nat. Nanotechnol. 2017, 12, 619-630.

23. Mayer, M.; Yang, J. Engineered Ion Channels as Emerging Tools for Chemical Biology. Acc. Chem. Res. 2013, 46, 2998-3008.

24. Langecker, M.; Arnaut, V.; List, J.; Simmel, F. C. DNA Nanostructures Interacting with Lipid Bilayer Membranes. Acc. Chem. Res. 2014, 47, 1807-1815.

25. Fyles, T. M. Synthetic Ion Channels in Bilayer Membranes. Chem. Soc. Rev. 2007, 36, $335-347$.

26. Bell, N. A.; Keyser, U. F. Nanopores Formed by DNA Origami: A Review. FEBS Lett. 2014, 588, 3564-3570.

27. Shi, W.; Friedman, A. K.; Baker, L. A. Nanopore Sensing. Anal. Chem. 2017, 89, 157188. 
28. Lan, W. J.; Edwards, M. A.; Luo, L.; Perera, R. T.; Wu, X. J.; Martin, C. R.; White, H. S. Voltage-Rectified Current and Fluid Flow in Conical Nanopores. Acc. Chem. Res. 2016, 49, 2605-2613.

29. Majd, S.; Yusko, E. C.; Billeh, Y. N.; Macrae, M. X.; Yang, J.; Mayer, M. Applications of Biological Pores in Nanomedicine, Sensing, and Nanoelectronics. Curr. Opin. Biotechnol. 2010, 21, 439-476.

30. Ayub, M.; Bayley, H. Engineered Transmembrane Pores. Curr. Opin. Chem. Biol. 2016, 34, 117-126.

31. Hille, B. Ion Channels of Excitable Membranes. 3rd ed.; Sinauer Associates: 2001.

32. Chowdhury, S.; Jarecki, B. W.; Chanda, B. A Molecular Framework for TemperatureDependent Gating of Ion Channels. Cell 2014, 158, 1148-1158.

33. Kocer, A.; Walko, M.; Meijberg, W.; Feringa, B. L. A Light-Actuated Nanovalve Derived from a Channel Protein. Science 2005, 309, 755-758.

34. Allen, T. M.; Cullis, P. R. Liposomal Drug Delivery Systems: From Concept to Clinical Applications. Adv. Drug Deliv. Rev. 2013, 65, 36-48.

35. Thomson, A. R.; Wood, C. W.; Burton, A. J.; Bartlett, G. J.; Sessions, R. B.; Brady, R. L.; Woolfson, D. N. Computational Design of Water-Soluble Alpha-Helical Barrels. Science 2014, 346, 485-488.

36. Joh, N. H.; Wang, T.; Bhate, M. P.; Acharya, R.; Wu, Y.; Grabe, M.; Hong, M.; Grigoryan, G.; DeGrado, W. F. De Novo Design of a Transmembrane Zn(2)(+)-Transporting Four-Helix Bundle. Science 2014, 346, 1520-1524. 
37. Mahendran, K. R.; Niitsu, A.; Kong, L.; Thomson, A. R.; Sessions, R. B.; Woolfson, D. N.; Bayley, H. A Monodisperse Transmembrane Alpha-Helical Peptide Barrel. Nat. Chem. 2017, $9,411-419$.

38. Torring, T.; Voigt, N. V.; Nangreave, J.; Yan, H.; Gothelf, K. V. DNA Origami: A Quantum Leap for Self-Assembly of Complex Structures. Chem. Soc. Rev. 2011, 40, 5636-5646.

39. Fu, J.; Yang, Y. R.; Johnson-Buck, A.; Liu, M.; Liu, Y.; Walter, N. G.; Woodbury, N. W.; Yan, H. Multi-Enzyme Complexes on DNA Scaffolds Capable of Substrate Channelling with an Artificial Swinging Arm. Nat. Nanotechnol. 2014, 9, 531-536.

40. Wollman, A. J.; Sanchez-Cano, C.; Carstairs, H. M.; Cross, R. A.; Turberfield, A. J. Transport and Self-Organization across Different Length Scales Powered by Motor Proteins and Programmed by DNA. Nat. Nanotechnol. 2014, 9, 44-47.

41. Sacca, B.; Niemeyer, C. M. Functionalization of DNA Nanostructures with Proteins. Chem. Soc. Rev. 2011, 40, 5910-5921.

42. Zheng, J. P.; Birktoft, J. J.; Chen, Y.; Wang, T.; Sha, R. J.; Constantinou, P. E.; Ginell, S. L.; Mao, C. D.; Seeman, N. C. From Molecular to Macroscopic Via the Rational Design of a Self-Assembled 3d DNA Crystal. Nature 2009, 461, 74-77.

43. Rothemund, P. W. Folding DNA to Create Nanoscale Shapes and Patterns. Nature 2006, 440, 297-302.

44. Seeman, N. C. Nanomaterials Based on DNA. Annu. Rev. Biochem. 2010, 79, 65-87.

45. Chen, Y. J.; Groves, B.; Muscat, R. A.; Seelig, G. DNA Nanotechnology from the Test Tube to the Cell. Nat. Nanotechnol. 2015, 10, 748-760. 
46. Pinheiro, A. V.; Han, D.; Shih, W. M.; Yan, H. Challenges and Opportunities for Structural DNA Nanotechnology. Nat. Nanotechnol. 2011, 6, 763-772.

47. Jones, M. R.; Seeman, N. C.; Mirkin, C. A. Nanomaterials. Programmable Materials and the Nature of the DNA Bond. Science 2015, 347, 1260901.

48. Seeman, N. C.; Sleiman, H. F. DNA Nanotechnology. Nat. Rev. Mater. 2017, 3, 17068.

49. Douglas, S. M.; Marblestone, A. H.; Teerapittayanon, S.; Vazquez, A.; Church, G. M.; Shih, W. M. Rapid Prototyping of 3d DNA-Origami Shapes with Cadnano. Nucleic Acids Res. 2009, 37, 5001-5006.

50. Bell, N. A.; Engst, C. R.; Ablay, M.; Divitini, G.; Ducati, C.; Liedl, T.; Keyser, U. F. DNA Origami Nanopores. Nano Lett. 2012, 12, 512-517.

51. Langecker, M.; Arnaut, V.; Martin, T. G.; List, J.; Renner, S.; Mayer, M.; Dietz, H.; Simmel, F. C. Synthetic Lipid Membrane Channels Formed by Designed DNA Nanostructures. Science 2012, 338, 932-936.

52. Burns, J.; Stulz, E.; Howorka, S. Self-Assembled DNA Nanopores That Span Lipid Bilayers. Nano Lett. 2013, 13, 2351-2356.

53. Howorka, S. Nanotechnology. Changing of the Guard. Science 2016, 352, 890-891.

54. Burns, J. R.; Göpfrich, K.; Wood, J. W.; Thacker, V. V.; Stulz, E.; Keyser, U. F.; Howorka, S. Lipid Bilayer-Spanning DNA Nanopores with a Bifunctional Porphyrin Anchor. Angew. Chem. Int. Ed. 2013, 52, 12069-12072. 
55. Burns, J. R.; Al-Juffali, N.; Janes, S. M.; Howorka, S. Membrane-Spanning DNA Nanopores with Cytotoxic Effect. Angew. Chem. Int. Ed. 2014, 53, 12466-12470.

56. Seifert, A.; Göpfrich, K.; Burns, J. R.; Fertig, N.; Keyser, U. F.; Howorka, S. BilayerSpanning DNA Nanopores with Voltage-Switching between Open and Closed State. ACS Nano 2015, $9,1117-1126$.

57. Gopfrich, K.; Zettl, T.; Meijering, A. E.; Hernandez-Ainsa, S.; Kocabey, S.; Liedl, T.; Keyser, U. F. DNA-Tile Structures Induce Ionic Currents through Lipid Membranes. Nano Lett. 2015, 15, 3134-3138.

58. Krishnan, S.; Ziegler, D.; Arnaut, V.; Martin, T. G.; Kapsner, K.; Henneberg, K.; Bausch, A. R.; Dietz, H.; Simmel, F. C. Molecular Transport through Large-Diameter DNA Nanopores. Nat. Commun. 2016, 7, 12787.

59. Gopfrich, K.; Li, C. Y.; Ricci, M.; Bhamidimarri, S. P.; Yoo, J.; Gyenes, B.; Ohmann, A.; Winterhalter, M.; Aksimentiev, A.; Keyser, U. F. Large-Conductance Transmembrane Porin Made from DNA Origami. ACS Nano 2016, 10, 8207-8214.

60. Burns, J. R.; Seifert, A.; Fertig, N.; Howorka, S. A Biomimetic DNA-Based Channel for the Ligand-Controlled Transport of Charged Molecular Cargo across a Biological Membrane. Nat. Nanotechnol. 2016, 11, 152-156.

61. Yin, Y.; Zhao, X. S. Kinetics and Dynamics of DNA Hybridization. Acc. Chem. Res. 2011, 44, 1172-1181.

62. Jung, Y.; Bayley, H.; Movileanu, L. Temperature-Responsive Protein Pores. J. Am. Chem. Soc. 2006, 128, 15332-15340. 
63. Banghart, M.; Borges, K.; Isacoff, E.; Trauner, D.; Kramer, R. H. Light-Activated Ion Channels for Remote Control of Neuronal Firing. Nat. Neurosci. 2004, 7, 1381-1386.

64. Volgraf, M.; Gorostiza, P.; Numano, R.; Kramer, R. H.; Isacoff, E. Y.; Trauner, D. Allosteric Control of an Ionotropic Glutamate Receptor with an Optical Switch. Nat. Chem. Biol. 2006, 2, 47-52.

65. Gorostiza, P.; Volgraf, M.; Numano, R.; Szobota, S.; Trauner, D.; Isacoff, E. Y. Mechanisms of Photoswitch Conjugation and Light Activation of an Ionotropic Glutamate Receptor. Proc. Natl. Acad. Sci. U S A 2007, 104, 10865-10870.

66. Mantri, S.; Sapra, K. T.; Cheley, S.; Sharp, T. H.; Bayley, H. An Engineered Dimeric Protein Pore That Spans Adjacent Lipid Bilayers. Nat. Commun. 2013, 4.

67. Wickham, S. F.; Bath, J.; Katsuda, Y.; Endo, M.; Hidaka, K.; Sugiyama, H.; Turberfield, A. J. A DNA-Based Molecular Motor That Can Navigate a Network of Tracks. Nat. Nanotechnol. 2012, 7, 169-173.

68. Omabegho, T.; Sha, R.; Seeman, N. C. A Bipedal DNA Brownian Motor with Coordinated Legs. Science 2009, 324, 67-71.

69. Derr, N. D.; Goodman, B. S.; Jungmann, R.; Leschziner, A. E.; Shih, W. M.; ReckPeterson, S. L. Tug-of-War in Motor Protein Ensembles Revealed with a Programmable DNA Origami Scaffold. Science 2012, 338, 662-665.

70. Pugh, G. C.; Burns, J. R.; Howorka, S. Comparing Proteins and Nucleic Acids for NextGeneration Biomolecular Engineering. Nat. Rev. Chem. 2018, 2, 113-130. 
71. Ohmann, A.; Li, C. Y.; Maffeo, C.; Al Nahas, K.; Baumann, K. N.; Gopfrich, K.; Yoo, J.; Keyser, U. F.; Aksimentiev, A. A Synthetic Enzyme Built from DNA Flips 10(7) Lipids Per Second in Biological Membranes. Nat. Commun. 2018, 9, 2426.

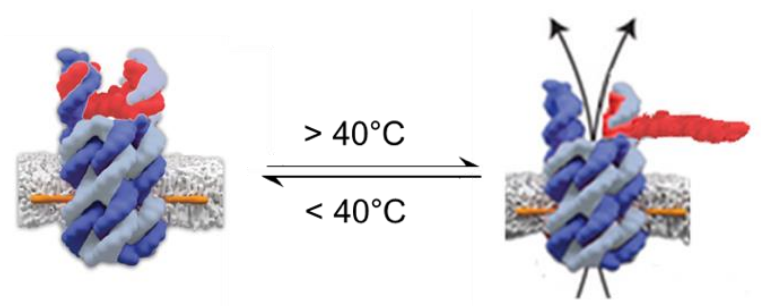

